\title{
Zimbabwe: CBD roles modified to address Zimbabwe's HIV/AIDS crisis
}

Frontiers in Reproductive Health

Follow this and additional works at: https://knowledgecommons.popcouncil.org/departments_sbsr-rh

Part of the Community Health and Preventive Medicine Commons, Demography, Population, and Ecology Commons, International Public Health Commons, and the Women's Health Commons How does access to this work benefit you? Let us know!

\section{Recommended Citation}

"Zimbabwe: CBD roles modified to address Zimbabwe's HIV/AIDS crisis," FRONTIERS OR Summary. Washington, DC: Population Council, 2002. 


\section{Zimbabwe Integration}

OR Summary 29

\section{CBD Roles Modified to Address Zimbabwe's HIVIAIDS Crisis}

\section{Background}

In September 1999 the Zimbabwe National Family Planning Council (ZNFPC) and the Population Council initiated a one-year study to assess the performance of ZNFPC's communitybased distribution (CBD) program. A continual decline in the program's productivity, combined with the expanding HIV/AIDS epidemic, indicated a need to reconsider ZNFPC's objectives and revise the roles and responsibilities of its full-time, salaried CBD agents.

The study examined the productivity, costs and potential sustainability of the CBD program. Researchers gathered information by reviewing program documents through 1999. They also interviewed program managers, district and community nurses, and community leaders (a total of 174 interviews) and CBD agents from each of the eight regions (a total of 128 agents). They assessed community views through 61 focus group discussions with female CBD clients, male and female users and non-users of family planning (FP), and youth.

\section{Findings}

- At the time of the study, the major responsibilities of ZNFPC agents were to educate clients on all available FP methods, supply shortterm methods (pills, condoms, and spermicides), and refer clients to clinics or hospitals for other methods or for management of side effects. Agents were also trained to provide advice on other aspects of health and information on preventing sexually transmitted infections including HIV/AIDS.

- The overall productivity of the CBD program declined in recent years (though records show only pill and condom distribution, not distribution of spermicides or provision of other services). Coupleyears of protection (CYP) from pills declined from 211,026 to $87,664(-58 \%)$ between 1991 and 1999 (see Figure). However, CYP from

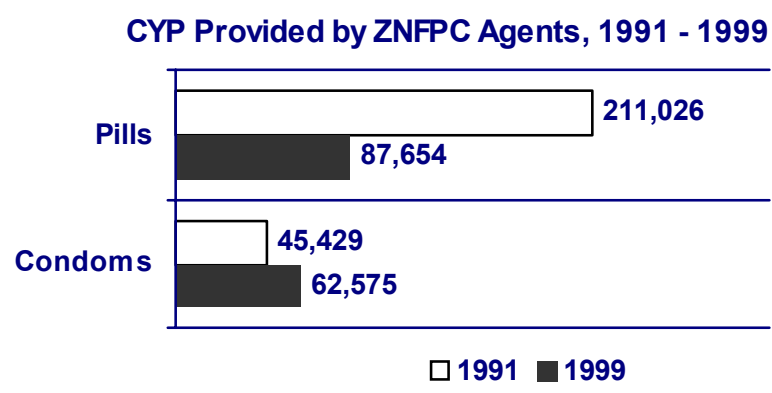

condoms increased by from 45,929 to 62,575 $(+36 \%)$ during the same period. Several factors may explain these changes:

$\downarrow$ There may be a tradeoff between offering increased protection from sexually transmitted infections and increasing CYP. 
$\nLeftarrow$ Alternative outlets for FP services have increased.

$\&$ Pill use has declined while use of other methods, such as the injectable, has increased.

\& ZNFPC agents, averaging 43 years old and originally trained to reach older, married women, may have difficulty reaching the emerging clientele of young, unmarried, better-educated individuals.

- ZNFPC's management information system (MIS) needs to be restructured to provide sufficient data for program management and planning. Agents claimed that they carried out numerous functions besides distribution of FP methods, such as counseling, referrals to clinics, or HIV/AIDS education; but daily monitoring systems did not require them to record these activities. Thus it was impossible to determine agents' true productivity or to calculate the cost-effectiveness of the CBD program.

- ZNFPC recovered 16 percent of its program costs through pill sales (condoms are distributed free because of the HIV/AIDS epidemic); but the agency still needs to reduce operating costs while maintaining its output.

\section{Utilization}

- ZNFPC, USAID, and the Population Council used the study findings to develop a proposal to revise and test a broader CBD program, in which agents' roles are expanded to encompass outreach on STIs including HIV/AIDS.

- Based on this proposal, ZNFPC is collaborating with the Advance Africa consortium on a pilot project to redirect its $\mathrm{CBD}$ program to include an expanded reproductive health agenda, particularly counseling and referrals related to STIs and HIV/ AIDS, home-based care, and voluntary counseling and testing for HIV/AIDS. The pilot program places increased emphasis on reaching currently under-served groups such as adolescents, men and low parity women. Fifty-five CBD agents and 222 supply depot holders were trained and are now implementing a pilot program in eight districts.

- Advance Africa is working with ZNFPC to develop improved monitoring and evaluation systems, train CBD agents in behavior change communication, establish linkages with HIV testing and counseling centers, and assess the cost and cost-effectiveness of service delivery.

\section{Policy Implications}

- CBD programs must be prepared to adapt their organizational objectives and procedures to meet changing national and local reproductive health needs. Programs can develop or maintain their organization readiness for change by:
$\nLeftarrow$ Establishing clear management information systems and a system of regular review of operations, agent performance, and cost recovery.
\& Reviewing organizational objectives and assessing their relevance to national family planning and reproductive health needs, and to the availability of services, including prevention of STIs and HIV/AIDS.
$\nLeftarrow$ Periodically conducting rigorous research, such as operations research, to assess program performance or test alternative approaches to service delivery.

Maggwa, Baker Ndugga et al. 2001. An Assessment of the Zimbabwe National Family Planning Council's Community-Based Distribution Programme. Nairobi: Population Council. For more information, contact: Population Council, P.O. Box 17643, Nairobi, Kenya. Tel. 254-2713-480; Fax: 254-2-713-479; E-mail:publications@popcouncil.or.ke.

This project was conducted with funds from the U.S. AGENCY FOR INTERNATIONAL DEVELOPMENT under Cooperative Agreement Number HRN-A-00-98-00012-00. 